\title{
Avaliação Automática da Qualidade de Objetos de Aprendizagem dentro de Repositórios
}

\author{
Automated Quality Assessment of Learning Objects inside Repositories
}

\section{Cristian Cechinel}

Centro de Educação a Distância (CEAD)

Universidade Federal de Pelotas - UFPEL

Félix da Cunha 630, Centro - Pelotas RS - 96010-000

contato@cristiancechinel.pro.br

\section{Miguel-Ángel Sicilia}

Information Engineering Research Unit,

Computer Science Dept., University of Alcalá

Ctra. Barcelona km. 33.6 - 28871 Alcalá de Henares (Ma-

drid), Espanha

msicilia@uah.es

\author{
Salvador Sánchez-Alonso \\ Information Engineering Research Unit, \\ Computer Science Dept., University of Alcalá \\ Ctra. Barcelona km. 33.6 - 28871 Alcalá de Henares (Ma- \\ drid), Espanha \\ salvador.sanchez@uah.es
}

\begin{abstract}
Resumo À medida que a quantidade de objetos de aprendizagem (OAs) cresce rapidamente dentro dos repositórios, aumenta a necessidade de desenvolver novas abordagens para a avaliação da qualidade dos mesmos sem depender exclusivamente do trabalho humano. A disponibilidade de metadados avaliativos dentro de alguns repositórios abriu a possibilidade de contrastar características intrínsecas dos OAs permitindo descobrir medidas associadas com a qualidade dos mesmos e que podem ser utilizadas no processo de geração de modelos para a avaliação automática da qualidade. O presente trabalho descreve os primeiros resultados obtidos com tal abordagem utilizando informações coletadas do repositório MERLOT. Os resultados encontrados aqui apontam para a exequibilidade da abordagem para os subconjuntos avaliados, e reforçam a ideia de que os modelos para avaliação automática da qualidade devem ser desenvolvidos levando em consideração as diversas combinações possiveis entre as categorias de disciplina e os tipos de materiais disponíveis no repositório. O trabalho também apresenta dois possíveis cenários para a utilização dos modelos dentro de um repositório.
\end{abstract}

Palavras-Chave: Objetos de Aprendizagem, Repositórios, Avaliação Automática da Qualidade.

\begin{abstract}
As the amount of learning objects is rapidly growing inside the existing repositories, there is an urgent need to create new approaches for evaluating their quality without relying only on human work. The availability of evaluative metadata inside some repositories has opened the possibility of contrasting intrinsic features of the resources in order to discover metrics associated to quality that can be used for the generation of models for automated quality assessment. The present work describes the first results of such approach by using data of learning objects collected from the MERLOT repository. The results found here point out the feasibility of such approach for the evaluated subsets, and reinforce that models for automated quality assessment must be developed taking into consideration the many possible combinations of categories of discipline and types of materials available in the repository. The present work also presents two possible usage scenarios for the models once they are implemented inside a repository.
\end{abstract}

Keywords: Learning Objects, Repositories, Automated Quality Assessment

Recebido: 29 de Novembro de 2012 / Aceito: 12 Dezembro de 2012

DOI: $10.5753 /$ RBIE.2012.20.03.43 


\section{Introdução}

Objetos de aprendizagem (OAs) são normalmente definidos como recursos digitais que podem ser utilizados e reutilizados em contextos educacionais de maneira a ajudar no processo de ensino e aprendizagem. Diversas abordagens para avaliação da qualidade dos OAs vem sendo propostas nos últimos anos [1] [2] [3] [4] [5] [6], entretanto ainda não existe consenso sobre o que exatamente constitui um objeto de boa qualidade, nem tampouco sobre qual a melhor maneira de conduzir o processo de avaliação da qualidade. Na realidade, como a própria definição do termo "objeto de aprendizagem" ainda é motivo de controvérsias e discussões, não é difícil inferir que o seu conceito de qualidade irá depender dessas muitas definições existentes e dos inúmeros contextos em que esses recursos são utilizados.

A grande disseminação de OAs na internet tornou impraticável depender somente do esforço humano para avaliar a qualidade desses recursos, e criou a necessidade de alternativas de avaliação automática que pudessem minimizar tal trabalho. A atual abundância de OAs dentro de repositórios [7] e a disponibilidade de informações contextuais sobre os mesmos que são fornecidas pela comunidade de usuários - também chamados de metadados avaliativos (evaluative metadata) [8] - abriu a possibilidade de buscar por medidas intrínsecas dos OAs que possam servir como potenciais indicadores de qualidade, e que por sua vez, possam ser utilizadas na geração de modelos para a avaliação automática dos mesmos. Em outras palavras, OAs que contêm metadados avaliativos (pontuações, comentários, recomendações) podem ser divididos em classes de acordo com a qualidade associada a eles (por exemplo, entre bons e não-bons) e suas informações intrínsecas podem ser comparadas com o objetivo de verificar se existem diferenças significativas entre essas classes. As medidas intrínsecas que apresentam diferenças entre as classes são a base para o desenvolvimento de perfis de OAs altamente pontuados (de alta qualidade) que por sua vez podem ser utilizados no desenvolvimento de modelos para a avaliação automática da qualidade dos recursos.

Tal abordagem foi anteriormente aplicada com sucesso por [9] na área de avaliação da qualidade de websites, onde os autores desenvolveram perfis de websites altamente pontuados com base nas notas (ratings) dadas pelos juízes do 2000 Webby Awards ${ }^{1}$.

Mais recentemente, [10] desenvolveram perfis de

\footnotetext{
${ }^{1}$ Prêmio internacional de reconhecimento pela excelência de websites concedido pela Academia Internacional de Artes e Ciências. http://www.webbyawards.com/index.php.
}

OAs altamente pontuados disponíveis no repositório MERLOT e geraram modelos utilizando Análise Discriminante Linear (LDA) com base em 13 características intrínsecas dos OAs. Os modelos gerados foram capazes de classificar recursos entre bom e não-bom com 72,16\% de precisão e entre bom e ruim com $91,49 \%$ de precisão. Entre outras conclusões, os autores relataram que os perfis de OAs altamente pontuados devem ser desenvolvidos levando em consideração as muitas possibilidades de intersecções entre as diferentes disciplinas e tipos de materiais existentes no MERLOT, assim como também os diferentes grupos de avaliadores que pontuaram os recursos (se são formados por especialistas ou pela comunidade de usuários). Por exemplo, os modelos mencionados foram criados para materiais do tipo Simulação que pertencem à disciplina de Ciência e Tecnologia, e considerando a perspectiva das pontuações fornecidas pelos avaliadores especialistas (peer-reviewer ratings).

No trabalho anteriormente mencionado foram testados apenas modelos LDA para a avaliação de qualidade dos recursos do tipo Simulação pertencentes à disciplina de Ciência e Tecnologia. Em um segundo trabalho [11] os autores também testaram modelos para dois novos subconjuntos e utilizando mineração de dados a partir de cinco algoritmos de classificação diferentes. Apesar dos autores terem encontrado resultados inicialmente favoráveis (com classificação correta da qualidade de aproximadamente $85 \%$ dos OAs), tais resultados apresentavam apenas os percentuais de classificação geral de cada modelo. O presente trabalho continua a investigação iniciada por [10] e [11] a partir da avaliação detalhada do desempenho dos modelos para a avaliação automática da qualidade dos OAs gerados a partir de LDA e a partir dos seguintes algoritmos de classificação: J48, SimpleCart, PART, Rede Neural Multilayer Perceptron e Redes Bayesianas. Esse trabalho também descreve dois possíveis cenários para a utilização dos modelos uma vez que os mesmos estejam devidamente implementados em um repositório, sendo que cada cenário envolve atores diferentes e acontecem em estágios particulares do ciclo de vida de um OA.

O restante desse artigo está estruturado da seguinte maneira: a seção 2 apresenta brevemente alguns trabalhos relacionados com a avaliação automática de OAs. A seção 3 descreve o repositório MERLOT e os metadados avaliativos mais importantes disponíveis no mesmo. A seção 4 explica a metodologia aplicada no presente estudo e a seção 5 apresenta os principais resultados alcançados com os modelos gerados. Na seção 6 são discutidos dois cenários de utilização dos modelos para avaliação automática da qualidade de OAs dentro de repositórios e na seção 7 são apresentadas as conclusões desse trabalho, algumas limitações e possibilidades de trabalhos futuros 
dentro dessa área.

\section{Trabalhos Relacionados}

Até o presente momento, uma das iniciativas mais tangíveis em direção a avaliação automática de OAs é o trabalho de [12] que propõe o desenvolvimento de um conjunto de métricas para ranquear os resultados de busca por OAs dentro de repositórios. Nesse trabalho, os autores se referem ao conceito de qualidade como a relevância que algum recurso apresenta em um contexto de uso específico [13] usando como fonte de inspiração métodos normalmente aplicados para ranquear outros tipos de objetos, como por exemplo: livros (filtragem colaborativa) e artigos científicos (fator de impacto). Os autores agruparam as métricas propostas de acordo com três dimensões de relevância, sendo elas: tópico (o que é de interesse do usuário), pessoal (por quê o usuário está interessado naquele tópico) e situacional (onde o recurso instrucional será utilizado); e contrastaram seus desempenhos com o desempenho de métodos tradicionais de ranqueamento baseados em texto, encontrando melhoras significativas nos resultados finais de ranqueamento. No presente trabalho, estamos propondo uma abordagem diferente, baseada somente nos dados que estão disponíveis nos próprios OAs. A ideia principal é de que a avaliação automática da qualidade será tipicamente utilizada em OAs que ainda não foram compartilhados com o público e que, portanto ainda não possuem nenhuma informação de uso a eles associada.

De nosso conhecimento, além dos trabalhos recentes de [10] e [11], ainda não existem evidências empíricas definitivas de medidas intrínsecas que possam servir como indicadores de qualidade dos OAs. Entretanto, existem alguns trabalhos em áreas adjacentes que podem servir como fonte de inspiração. Por exemplo, evidências empíricas de relações entre informações intrínsecas e outras características dos OAs foram encontradas em [14], onde os autores desenvolveram um modelo para classificar as funções didáticas de um $\mathrm{OA}$ baseados em medidas sobre o tamanho do texto, a presença de interatividade e informações contidas no código HTML (listas, formulários, elementos de entrada). Em [15] foram identificadas evidências em algumas medidas para avaliar a sustentabilidade e a reusabilidade de aplicações de hipermídia educacional, tais como, o tipo do link, e a estrutura e tamanho da aplicação. Em outro experimento, [16] confirmaram a possibilidade de decompor o conceito de qualidade de recursos educacionais em pedaços pequenos de dimensões mensuráveis, abrindo o caminho para a caracterização automática de qualidade dentro de bibliotecas educacionais digitais. Nesse trabalho, os autores identificaram cinco indicadores de qualidade que podem ser automaticamente observados e medidos dentro de recursos educacionais a partir do uso de processamento de linguagem natural e técnicas de aprendizagem de máquina. Em [17], observou-se que o tamanho de um artigo (medido em palavras) pode ser considerado como um prognosticador de qualidade na Wikipédia. Por último, na área da usabilidade, [9] concluíram que bons websites contêm (por exemplo) um maior número de palavras e links do que os websites normais e os considerados ruins.

Nossa abordagem está exclusivamente relacionada com aqueles aspectos de OAs que são exibidos para os usuários e que são normalmente associados às dimensões de "apresentação de projeto" e "usabilidade de interação" (incluídas no LORI [3]) e a dimensão de "qualidade da informação" (normalmente mencionada no contexto de bibliotecas educacionais digitais). Precisamente, as referências utilizadas como base para medir a qualidade dos OAs nesse trabalho são as pontuações dadas aos OAs pela comunidade de especialistas do repositório MERLOT.

\section{O Repositório MERLOT}

O MERLOT (Multimedia Educational Resource for Learning and Online Teaching ${ }^{1}$ ) é um repositório que permite que usuários cataloguem recursos educacionais tendo como objetivo a utilização e o compartilhamento de tecnologias de aprendizagem online [18]. Esse repositório contem metadados sobre materiais de aprendizagem classificados de acordo com diferentes categorias de disciplina e outras características, tais como: objetivo pedagógico, granularidade, e formato técnico. O repositório possui um robusto sistema de avaliação da qualidade que é baseado em diferentes tipos de metadados avaliativos (comentários e notas dos usuários e especialistas, prêmios, e favoritos).

Os recursos no MERLOT estão organizados em 7 disciplinas distintas: Artes, Negócios, Educação, Humanas, Matemática e Estatística, Ciência e Tecnologia, e Ciências Sociais, que por sua vez também estão subdivididas em diversas subcategorias. Quando o usuário cadastra um novo recurso no repositório, além da disciplina, o mesmo deve também preencher o tipo do material, que pode estar em uma das seguintes classes: Animação, Ferramenta de Avaliação, Tarefa, Estudo de Caso, Coleção, Ferramenta de Desenvolvimento, Exercício e Prática, Repositório de Objetos de Aprendizagem, Curso Online, Jornal ou Artigo Aberto, Livro Texto Aberto, Aula/Apresentação, Material de Referência, Simulação, Ferramenta de Redes Sociais, Tutorial, Exame/Teste, Material para Treinamento e Workshop.

Com o objetivo de garantir a qualidade dentro do repositório, o MERLOT adota um modelo de revisão por pares [18], onde os materiais já catalogados são revisados

\footnotetext{
${ }^{1}$ www.merlot.org
} 
por especialistas membros da comissão editorial de alguma comunidade de disciplina (Artes, Matemática, Negócios, entre outras). As comissões editoriais do MERLOT decidem sobre o processo de selecionar os materiais que consideram dignos de serem avaliados, e esses materiais selecionados são então revisados e pontuados pelos pares. Após esse processo, o editor chefe da comissão compõe um único relatório (e uma média das notas) e publica o mesmo no repositório. Além da avaliação por pares, o MERLOT também permite que usuários registrados no repositório forneçam comentários e notas sobre os materiais, complementando a sua estratégia de avaliação com um mecanismo mais informal. As notas de ambos (usuários e revisores) variam entre 1 e 5 (com 5 como a melhor pontuação).

Ainda, o MERLOT permite que seus usuários adicionem os recursos em coleções pessoais, fornecendo uma maneira dos mesmos organizarem seus materiais favoritos de acordo com seus interesses individuais [19]. Por último, o MERLOT concede anualmente um prêmio especial (MERLOT Classics Awards) para recursos excepcionais de acordo com um conjunto de critérios estabelecidos para as disciplinas. Todos esses metadados avaliativos juntos são então utilizados na ordenação dos materiais quando um usuário realiza uma busca dentro do repositório.

\section{Metodologia}

A metodologia do presente trabalho foi o desenvolvimento de perfis de OAs altamente pontuados no repositório MERLOT. O estudo foi restringido a algumas intersecções de categorias de disciplinas e tipos de materiais existentes no repositório no contexto das pontuações dadas pelos especialistas da área. Essa metodologia está baseada nas metodologias aplicadas e descritas em [9] e [10]. Os perfis criados foram então utilizados para gerar modelos para a avaliação automática da qualidade de OAs pertencentes aos conjuntos intersectados. A figura 1 apresenta uma ideia geral da metodologia aplicada nesse trabalho.

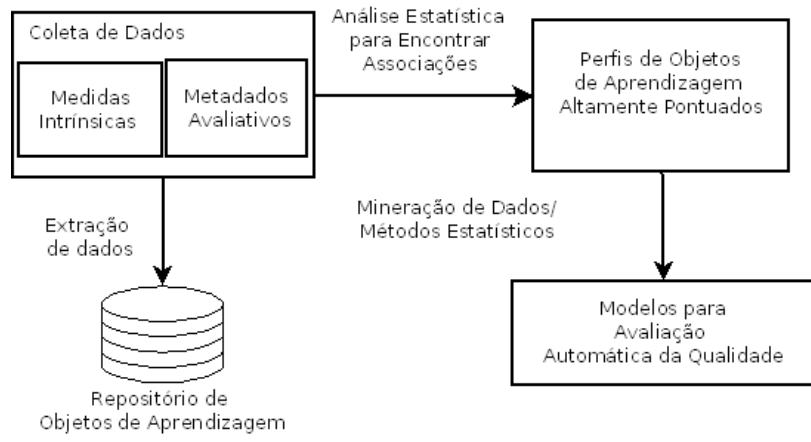

Figura 1: Visão geral da metodologia utilizada

\subsection{Coleta de Dados}

Uma base de dados com 35 medidas foi coletada do MERLOT por meio de um crawler [20] que atravessou sistematicamente as páginas do repositório. Tendo em vista que o MERLOT é principalmente formado por OAs na forma de websites, foram avaliadas medidas intrínsecas que se supõem aparecer nesse tipo de material (i.e., medidas de link, de texto, gráficas e de arquitetura do website). Ainda, considerando que os recursos no MERLOT variam consideravelmente em tamanho, um limite de 2 níveis de profundidade foi estabelecido para o crawler, i.e., as medidas foram computadas para o nodo raiz (nível 0 - a home Page do recurso), assim como para as páginas ligadas ao nodo raiz (nível 1) e para as páginas ligadas pelas páginas ligadas ao nível 1 (nível 2). A tabela 1 apresenta as medidas coletadas. As medidas apresentadas na tabela referem-se a soma total de ocorrências de um determinado atributo considerando todo o OA. Além dessas medidas também foram coletadas algumas referentes às médias dessas somas considerando o número de páginas computadas para o OA. Por exemplo, um OA composto por 3 páginas e contendo um total de 30 imagens terá um total de imagens igual a 30 e um número médio de imagens igual a 10 (30/3). Informações de um total de 6.470 OAs foram coletadas. Desse conjunto de dados, somente 1.126 possuíam notas dadas por especialistas, tendo sido estas as utilizadas para o estudo.

\begin{tabular}{|c|c|}
\hline Classe da Medida & Medida \\
\hline Medidas de Link & $\begin{array}{l}\text { Número de Links, Número de } \\
\text { Links Únicos, Número de } \\
\text { Links Internos, Número de } \\
\text { Links Internos Únicos, } \\
\text { Número de Links Externos, } \\
\text { Número de Links Externos } \\
\text { Únicos }\end{array}$ \\
\hline Medidas de Texto & $\begin{array}{l}\text { Número de Palavras, Número } \\
\text { de Palavras que são Links }\end{array}$ \\
\hline $\begin{array}{l}\text { Medidas Gráfi- } \\
\text { cas, de Intera- } \\
\text { tividade e Mul- } \\
\text { timidia }\end{array}$ & $\begin{array}{l}\text { Número de Imagens, Tamanho } \\
\text { Total das Imagens (em } \\
\text { bytes), Número de Scripts, } \\
\text { Número de Applets, Número } \\
\text { de Arquivos de Áudio, Núme- } \\
\text { ro de Arquivos de Vídeo, } \\
\text { Número de Arquivos Multimí- } \\
\text { dia }\end{array}$ \\
\hline $\begin{array}{l}\text { Medidas de Ar- } \\
\text { quitetura do } \\
\text { Website }\end{array}$ & $\begin{array}{l}\text { Tamanho da Página (em } \\
\text { bytes), Número de Arquivos } \\
\text { para Download, Número Total } \\
\text { de Páginas }\end{array}$ \\
\hline
\end{tabular}

Tabela 1. Medidas Utilizadas no Estudo

A amostra coletada continha OAs classificados nas 7 categorias de disciplinas existentes e em 9 tipos de materiais (Animação, Estudo de Caso, Coleção, Exercício, Aula/Apresentação, Teste, Material de Referência, Simu- 
lação e Tutorial), totalizando 63 possíveis classes diferentes para criação de perfis de OAs. De acordo com o que foi apresentado em um estudo anterior [21], os OAs no MERLOT apresentam percentuais de ocorrências bastante distintos entre as diversas classes, com alguns subconjuntos contendo muito mais recursos do que outros. A tabela 2 apresenta as ocorrências dos OAs para cada um dos subconjuntos intersectados ${ }^{1}$.

\begin{tabular}{|c|c|c|c|c|}
\hline $\begin{array}{c}\text { Tipo de } \\
\text { Material/ } \\
\text { Disciplina }\end{array}$ & Artes & Negócios & $\begin{array}{c}\text { Educa- } \\
\text { ção }\end{array}$ & $\begin{array}{c}\text { Huma- } \\
\text { nas }\end{array}$ \\
\hline An imação & 6 & 4 & 7 & 9 \\
\hline $\begin{array}{l}\text { Estudo de } \\
\text { Caso }\end{array}$ & 1 & 17 & 11 & 5 \\
\hline Coleção & 17 & 24 & 36 & 68 \\
\hline Exercício & 2 & 21 & 6 & 24 \\
\hline $\begin{array}{l}\text { Aula/ } \\
\text { Apresenta- } \\
\text { Ção }\end{array}$ & 8 & 28 & 16 & 25 \\
\hline Teste & 3 & 7 & 8 & 7 \\
\hline $\begin{array}{l}\text { Material } \\
\text { de Refe- } \\
\text { rência }\end{array}$ & 18 & 40 & 43 & 31 \\
\hline Simulação & 12 & 16 & 13 & 16 \\
\hline Tutorial & 12 & 47 & 37 & 39 \\
\hline Total & 79 & 204 & 177 & 224 \\
\hline $\begin{array}{c}\text { Tipo de } \\
\text { Material/ } \\
\text { Disciplina }\end{array}$ & $\begin{array}{c}\text { Mate- } \\
\text { máti- } \\
\text { ca e } \\
\text { Esta- } \\
\text { tís- } \\
\text { tica }\end{array}$ & $\begin{array}{c}\text { Ciência } \\
\text { e Tecno- } \\
\text { logia }\end{array}$ & $\begin{array}{l}\text { Ciên- } \\
\text { cias } \\
\text { Soci- } \\
\text { ais }\end{array}$ & Total \\
\hline Animação & 18 & 32 & 2 & 78 \\
\hline $\begin{array}{l}\text { Estudo de } \\
\text { Caso }\end{array}$ & 3 & 9 & 2 & 48 \\
\hline Coleção & 12 & 25 & 9 & 191 \\
\hline Exercício & 5 & 6 & 1 & 65 \\
\hline $\begin{array}{l}\text { Aula/ } \\
\text { Apresenta- } \\
\text { ção }\end{array}$ & 7 & 45 & 11 & 140 \\
\hline Teste & 0 & 4 & 3 & 32 \\
\hline $\begin{array}{l}\text { Material } \\
\text { de Refe- } \\
\text { rência }\end{array}$ & 12 & 48 & 8 & 200 \\
\hline Simulação & 83 & 97 & 12 & 249 \\
\hline
\end{tabular}

${ }^{1}$ Como alguns OAs são classificados em mais de uma disciplina, existe uma sobreposição nos grupos. Esse é o motivo pelo qual a soma total da tabela 2 é equivalente a 1.257 e não a 1.126 .

\begin{tabular}{l|llll}
\hline Tutorial & 24 & 83 & 12 & 254 \\
\hline Total & 164 & 349 & 60 & 1.257 \\
\hline
\end{tabular}

Tabela 2. Número de ocorrências de OAs em cada subconjunto

Para esse estudo, foram selecionados os 3 subconjuntos com a maior quantidade de ocorrências, sendo eles: Simulação $\cap$ Ciência e Tecnologia, Simulação $\cap$ Matemática e Estatística, e Tutorial $\cap$ Ciência e Tecnologia.

\subsection{Gerando os perfis de OAs altamente pon- tuados}

Para descobrir quais medidas podem ser utilizadas como potenciais indicadores de qualidade, foram geradas classes de recursos bons, médios e ruins, utilizando os tercis das notas dadas pelos especialistas. OAs com notas abaixo do primeiro limite foram classificados como ruins $^{2}$, OAs com notas entre os dois limites foram classificadas como médios, e OAs com notas maiores ou iguais ao segundo limite foram classificados como bons. Como mencionado anteriormente, apenas OAs com uma ou mais notas dadas por especialistas foram incluídos no estudo. A tabela 3 apresenta os tercis encontrados para cada um dos 3 subconjuntos analisados nesse artigo.

\begin{tabular}{l|ll}
\hline \multicolumn{1}{c|}{ Subconjunto } & Tamanho & $\begin{array}{c}\text { Tercis das } \\
\text { Notas } \\
\text { dos Especia- } \\
\text { listas }\end{array}$ \\
\hline $\begin{array}{l}\text { Simulação ก Ciência } \\
\text { e Tecnologia }\end{array}$ & 97 & $3 \mid 4$ \\
$\begin{array}{l}\text { Simulação ก Matemá- } \\
\text { tica e Estatística }\end{array}$ & 83 & $4 \mid 4,75$ \\
$\begin{array}{l}\text { Tutorial } \cap \text { Ciência e } \\
\text { Tecnologia }\end{array}$ & 83 & $4 \mid 4,75$ \\
\hline
\end{tabular}

Tabela 3. Tercis dos subconjuntos

Como pode ser visto na tabela 3 , os limites para materiais bons são relativamente altos, acima da nota intermediária 3. A análise foi conduzida de maneira a contrastar as medidas intrínsecas entre os grupos de recursos bons e não-bons ${ }^{3}$, e observando se os mesmos apresentam diferenças significativas entre eles. Como as amostras não seguem uma distribuição normal, um teste de MannWhitney (Wilcoxon) foi executado para avaliar se as classes apresentam diferenças entre suas medianas, e um teste de Kolmogorov-Smirnov foi aplicado para avaliar se as classes apresentam distribuições diferentes. Quando ambas (distribuições e medianas) apresentam diferenças

\footnotetext{
${ }^{2}$ É importante ressaltar que o rótulo ruim não significa necessariamente que o recurso é de baixa qualidade, apenas que o mesmo encontra-se mal pontuado dentro do repositório.

${ }^{3} \mathrm{O}$ grupo chamado não-bons é formado pela união dos grupos médio e ruim
} 
significativas, a medida é então considerada como um potencial indicador de qualidade. A tendência de cada medida (se a mesma influencia positivamente ou negativamente a qualidade do OA) foi observada a partir da comparação entre as medianas dos valores das amostras. A tabela 4 apresenta as medidas que estão associadas aos

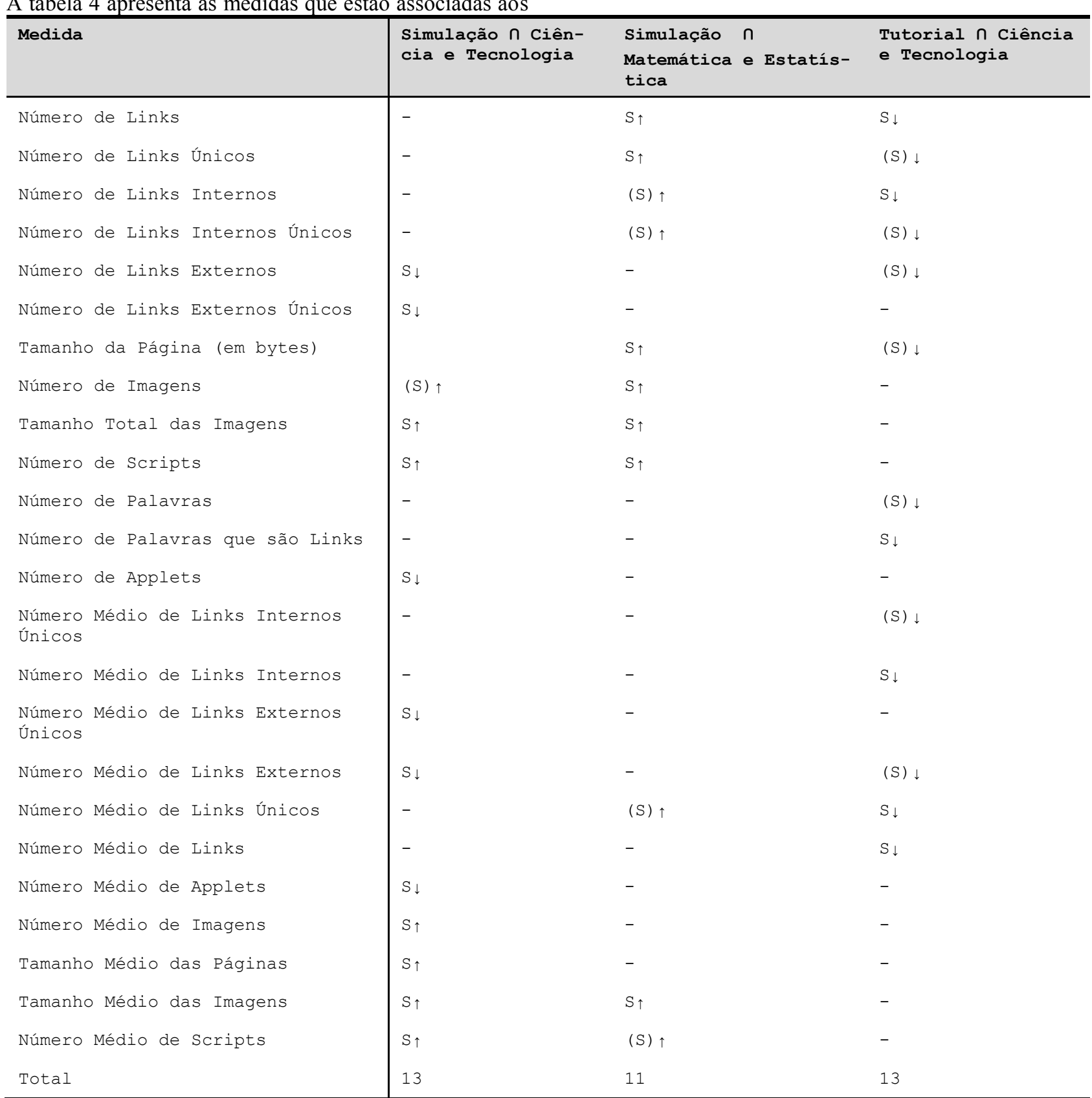

Nota: $S$ representa diferenças significativas em ambas as medidas (medianas e distribuições) ao mesmo tempo. A análise geral foi conduzida a um nível de significância de 95\%; uma informação entre parêntesis significa que o resultado foi significante apenas a um de confiança de $90 \%$. Ainda, $(\uparrow)$ significa uma tendência positiva e $(\downarrow)$ uma tendência negativa.

Tabela 4. Medidas identificadas como potenciais indicadores de qualidade e suas tendências para cada subconjunto

Como pode ser visto na tabela 4 , as medidas apresentam diferentes associações e tendências dependendo dos subconjuntos. Por exemplo, para o subconjunto Simula-
OAs altamente pontuados e suas respectivas tendências para cada subconjunto. 
Simulação $\cap$ Matemática e Estatística, todas as medidas que estão associadas com qualidade apresentam tendências positivas, e para o subconjunto Tutorial $\cap$ Ciência e Tecnologia todas as medidas associadas com qualidade apresentam tendências negativas. Ainda, nenhuma das medidas testadas apresentou associações com qualidade para os 3 subconjuntos ao mesmo tempo.

É também interessante ressaltar que subconjuntos com o mesmo tipo de disciplina, ou de tipo de material, preservam as tendências de suas medidas associadas com qualidade. Por exemplo, as 5 medidas que estão simultaneamente associadas a qualidade nos subconjuntos Simulação $\cap$ Ciência e Tecnologia e Simulação $\cap$ Matemática e Estatística (ambos contendo materiais de simulação) estão todas tendendo a uma associação positiva (Número de Imagens, Tamanho Total das Imagens, Número de Scripts, Tamanho Médio das Imagens, Número Médio de Scripts). Ainda, as 2 medidas que apresentam simultaneamente associações com qualidade nos subconjuntos Simulação $\cap$ Ciência e Tecnologia e Tutorial $\cap$ Ciência e Tecnologia (ambas com o mesmo tipo de disciplina) estão todas tendendo a uma associação negativa (Número de Links Externos e Número Médio de Links Externos). Por último, todas as medidas simultaneamente associadas a qualidade nos 2 subconjuntos que não possuem o mesmo tipo de material nem de disciplina (Simulação $\cap$ Matemática e Estatística e Tutorial $\cap$ Ciência e Tecnologia) apresentam tendências opostas (Número de Links, Número de Links Únicos, Número de Links Internos, Número de Links Internos Únicos, Tamanho da Página, Número Médio de Links Únicos).

A persistência dessas tendências poderia ser uma indicação de que a associação à qualidade dessas medidas específicas está vindo do grupo coincidente de tipo de material (ou de categoria de disciplina), e que então apareceria em outros conjuntos intersectados que envolvem esses tipos de recursos. Isso significa dizer, por exemplo, que a tendência positiva das medidas Número de Imagens, Tamanho Total das Imagens, Número de Scripts, Tamanho Médio das Imagens, e Número Médio de Scripts é uma associação mais relacionada aos materiais do tipo Simulação do que aos materiais dos subconjuntos Simulação $\cap$ Ciência e Tecnologia e Simulação $\cap M a$ temática e Estatística.

\section{Os Modelos}

\subsection{LDA}

Foi utilizada Análise Discriminante Linear (LDA) na construção de modelos para distinguir os OAs entre bons e não-bons, entre bons e médios, entre bons e ruins, e entre bons, médios e ruins para os 3 subconjuntos mencionados. Esse método é apropriado para classificar objetos em um ou mais grupos com base nas características que descrevem os mesmos. Para construir esses modelos foram utilizadas as medidas anteriormente identificas como potenciais indicadores de qualidade em cada subconjunto.

As tabelas 5, 6 e 7 apresentam as precisões das predições para cada um dos 4 modelos desenvolvidos para os 3 subconjuntos. Nas tabelas, a correlação canônica quadrada representa o percentual de variância das medidas explicadas pela função discriminante, e a precisão $d a$ classificação representa o percentual de sucesso atingido pelo modelo na categorização em cada grupo.

Como pode ser observado na tabela 5 , todos os 4 modelos desenvolvidos para o subconjunto Simulação $\cap$ Ciência e Tecnologia foram capazes de classificar os recursos dentro de um certo nível de significância $(90 \%$, $95 \%$ ou $99 \%$ ). Por outro lado, apenas um único modelo (modelo 2) desenvolvido para o subconjunto Simulação $\cap$ Matemática e Estatística (Tabela 6) foi capaz de classificar recursos corretamente e a um nível de significância de $90 \%$. Os piores resultados encontrados foram para o subconjunto Tutorial $\cap$ Ciência e Tecnologia (Tabela 7), onde nenhum dos modelos foi capaz de classificar corretamente os recursos dentro de um nível de significância aceitável $(90 \%, 95 \%$ ou $99 \%)$.

Para o subconjunto Simulação $\cap$ Ciência e Tecnologia (Tabela 5), o modelo número 1, que classifica OAs entre bons e médios, possui o menor percentual de correlação canônica, o valor p mais alto $(0.0983)$ e a pior precisão na classificação geral $(71,08 \%)$. O segundo modelo apresenta resultados intermediários com uma precisão de classificação geral de $72,16 \%$ e estatisticamente significante a um nível de $95 \%$. O terceiro modelo, que classifica OAs entre bons e ruins, apresenta os melhores resultados entre os 4 modelos, alcançando $91,49 \%$ de precisão na classificação geral. Esse modelo possui também a melhor correlação canônica e é estatisticamente significante a um nível de $99 \%$. É interessante ressaltar que à medida que as classes incluídas nos modelos se distanciam qualitativamente umas das outras (e.g. bom e ruim são os grupos mais distantes, e bom e não-bom são o segundo mais distantes), os modelos de classificação apresentam um maior percentual de correlação canônica, são mais precisos e mais estatisticamente significantes. Por exemplo, o modelo para classificar OAs entre bom e ruim tem uma precisão geral de classificação de $91,49 \%$, uma correlação canônica de 0,81 e é estatisticamente significante a um nível de $99 \%$, enquanto que o modelo para classificar entre bom e médio possui uma precisão geral de classificação de $71,08 \%$ (aproximadamente $20 \%$ menor que a anterior), uma correlação canônica de apensas 0,46 (aproximadamente metade da anterior) é estatisticamente significante somente a um nível de $90 \%$. Isso ilustra como as medidas apresentam forças diferentes depen- 
dendo dos diferentes grupos que são contrastados assim como da distância qualitativa entre eles.

Para o subconjunto Simulação $\cap$ Matemática e Estatística (Tabela 6), o modelo 2 foi capaz de classificar entre recursos bons e não-bons com uma precisão geral de $73,49 \%$ a um nível de significância de $90 \%$. Aqui é importante ressaltar a similaridade desse modelo com o modelo 2 para o subconjunto Simulação $\cap$ Ciência e Tecnologia. Ambos os modelos são voltados para a classificação entre bons e não-bons, e ambos apresentaram uma precisão geral entre 72 e $74 \%$, e uma correlação canônica de aproximadamente 0,47 . Ainda, em ambos os casos, a precisão para a classificação de recursos nãobons é consideravelmente maior do que a precisão para classificar recursos bons. Para o subconjunto Tutorial $\cap$ Ciência e Tecnologia (Tabela 7), nenhum dos modelos atingiram um nível de significância mínimo aceitável.

\begin{tabular}{|c|c|c|c|c|c|c|c|c|c|}
\hline \multirow[t]{2}{*}{$\mathbf{N}$} & \multirow{2}{*}{$\begin{array}{l}\text { Classes no } \\
\text { Modelo }\end{array}$} & \multirow{2}{*}{$\begin{array}{l}\text { Número } \\
\text { de Medi- } \\
\text { das }\end{array}$} & \multirow{2}{*}{$\begin{array}{l}\text { Correlação } \\
\text { Canônica } \\
\text { Quadrada }\end{array}$} & \multirow{2}{*}{$\begin{array}{l}\text { Valor } \\
\text { P }\end{array}$} & \multicolumn{5}{|c|}{ Precisão da Classificação } \\
\hline & & & & & Bom & Médio & Ruim & Não-Bom & Geral \\
\hline 1 & Bom e Médio & $12 \mathrm{a}$ & 0,4688 & 0,0983 & $72,00 \%$ & $69,70 \%$ & - & - & $71,08 \%$ \\
\hline 2 & Bom e Não-Bom & 13 & 0,47700 & 0,0435 & $63,64 \%$ & - & - & $76,56 \%$ & $72,16 \%$ \\
\hline 3 & Bom e Ruim & 13 & 0,81130 & 0,0001 & $96,97 \%$ & - & $78,57 \%$ & - & $91,49 \%$ \\
\hline 4 & $\begin{array}{l}\text { Bom, Médio e } \\
\text { Ruim }\end{array}$ & 13 & 0,54510 & 0,0016 & $57,58 \%$ & $62,00 \%$ & $64,29 \%$ & - & $60,82 \%$ \\
\hline
\end{tabular}

${ }^{a}$ O Tamanho Médio das Páginas não foi incluído nesse modelo

Tabela 5. Resultados da Análise Discriminante Linear para o subconjunto Simulação $\cap$ Ciência e Tecnologia

\begin{tabular}{|c|c|c|c|c|c|c|c|c|c|}
\hline \multirow[t]{2}{*}{$\mathbf{N}$} & \multirow{2}{*}{$\begin{array}{l}\text { Classes no } \\
\text { Modelo }\end{array}$} & \multirow{2}{*}{$\begin{array}{l}\text { Número } \\
\text { de } \\
\text { Medidas }\end{array}$} & \multirow{2}{*}{$\begin{array}{l}\text { Correlação } \\
\text { Canônica } \\
\text { Quadrada }\end{array}$} & \multirow{2}{*}{$\begin{array}{l}\text { Valor } \\
\quad P\end{array}$} & \multicolumn{5}{|c|}{ Precisão da Classificação } \\
\hline & & & & & Bom & Médio & Ruim & Não-Bom & Geral \\
\hline 1 & Bom e Médio & 11 & 0,44661 & 0,1060 & $58,06 \%$ & $82,61 \%$ & - & - & $72,73 \%$ \\
\hline 2 & Bom e Não-Bom & 11 & 0,46900 & 0,0656 & $58,06 \%$ & - & - & $82,69 \%$ & $73,49 \%$ \\
\hline 3 & Bom e Ruim & 11 & 0,34624 & 0,9762 & $67,74 \%$ & - & $66,67 \%$ & - & $67,57 \%$ \\
\hline 4 & $\begin{array}{l}\text { Bom, Médio e } \\
\text { Ruim }\end{array}$ & 11 & 0,46971 & 0,5911 & $54,84 \%$ & $28,26 \%$ & $83,33 \%$ & - & $42,17 \%$ \\
\hline
\end{tabular}

Tabela 6. Resultados da Análise Discriminante Linear para o subconjunto Simulação $\cap$ Matemática e Estatística

\begin{tabular}{|c|c|c|c|c|c|c|c|c|c|}
\hline \multirow[t]{2}{*}{$\mathbf{N}$} & \multirow{2}{*}{$\begin{array}{l}\text { Classes no } \\
\text { Modelo }\end{array}$} & \multirow{2}{*}{$\begin{array}{l}\text { Número } \\
\text { de Medi- } \\
\text { das }\end{array}$} & \multirow{2}{*}{$\begin{array}{c}\text { Correlação } \\
\text { Canônica } \\
\text { Quadrada }\end{array}$} & \multirow{2}{*}{$\begin{array}{l}\text { Valor } \\
\text { P }\end{array}$} & \multicolumn{5}{|c|}{ Precisão da Classificação } \\
\hline & & & & & Bom & Médio & Ruim & Não-Bom & Geral \\
\hline 1 & Bom e Médio & 13 & 0,43866 & 0,5391 & $89,29 \%$ & $41,67 \%$ & - & - & $62,50 \%$ \\
\hline 2 & Bom e Não-Bom & 13 & 0,40412 & 0,4261 & $92,86 \%$ & - & - & $43,64 \%$ & $60,24 \%$ \\
\hline 3 & Bom e Ruim & 13 & 0,1795 & 0,6037 & $92,86 \%$ & - & $52,63 \%$ & - & $76,60 \%$ \\
\hline 4 & $\begin{array}{l}\text { Bom, Médio e } \\
\text { Ruim }\end{array}$ & 13 & 0,50222 & 0,1915 & $57,14 \%$ & $47,22 \%$ & $47,37 \%$ & - & $59,60 \%$ \\
\hline
\end{tabular}

Tabela 7. Resultados da Análise Discriminante Linear para o subconjunto Tutorial $\cap$ Ciência e Tecnologia 


\begin{tabular}{|c|c|c|c|c|c|c|c|c|c|c|c|c|}
\hline \multirow{2}{*}{$\begin{array}{l}\text { Algoritmo de } \\
\text { Classificação }\end{array}$} & \multirow[t]{2}{*}{$\mathbf{N}$} & \multirow{2}{*}{$\begin{array}{l}\text { Classes no } \\
\text { Modelo }\end{array}$} & \multirow{2}{*}{$\begin{array}{c}\text { Medidas } \\
\text { usadas } \\
\text { no mo- } \\
\text { delo* }\end{array}$} & \multirow{2}{*}{$\begin{array}{c}\text { Número } \\
\text { de } \\
\text { Fo- } \\
\text { Ihas/Re } \\
\text { gras }\end{array}$} & \multirow{2}{*}{$\begin{array}{l}\text { Tamanho } \\
\text { da Árvo- } \\
\text { re }\end{array}$} & \multirow[t]{2}{*}{ EAM } & \multirow[t]{2}{*}{$\mathrm{K}$} & \multicolumn{5}{|c|}{ Precisão da Classificação } \\
\hline & & & & & & & & Bom & Médio & Ruim & Não-Bom & Geral \\
\hline \multirow{2}{*}{ J48 } & 1 & $\begin{array}{l}\text { Bom e Não- } \\
\text { Bom }\end{array}$ & 2 & 3 & 5 & 0,31 & 0,38 & $33,33 \%$ & - & - & $98,43 \%$ & $76,29 \%$ \\
\hline & 2 & $\begin{array}{l}\text { Bom, Médio } \\
\text { e Ruim }\end{array}$ & 11 & 19 & 37 & 0,1 & 0,83 & $96,96 \%$ & $84,00 \%$ & $92,85 \%$ & - & $89,69 \%$ \\
\hline \multirow{2}{*}{ Simple Cart } & 3 & $\begin{array}{l}\text { Bom e Não- } \\
\text { Bom }\end{array}$ & 2 & 3 & 5 & 0,30 & 0,53 & $57,57 \%$ & - & - & $92,18 \%$ & $80,41 \%$ \\
\hline & 4 & $\begin{array}{l}\text { Bom, Médio } \\
\text { e Ruim }\end{array}$ & 8 & 14 & 27 & 0,15 & 0,76 & $90,90 \%$ & $86,00 \%$ & $71,40 \%$ & - & $85,57 \%$ \\
\hline \multirow{2}{*}{ PART } & 5 & $\begin{array}{l}\text { Bom e Não- } \\
\text { Bom }\end{array}$ & 5 & 4 & - & 0,28 & 0,38 & $33,33 \%$ & - & - & $98,43 \%$ & $76,29 \%$ \\
\hline & 6 & $\begin{array}{l}\text { Bom, Médio } \\
\text { e Ruim }\end{array}$ & 8 & 11 & - & 0,16 & 0,74 & $97,00 \%$ & $72,00 \% \%$ & $92,9 \%$ & - & $83,51 \%$ \\
\hline \multirow{2}{*}{$\begin{array}{l}\text { Rede Neural } \\
\text { Multilayer } \\
\text { Perceptron }\end{array}$} & 7 & $\begin{array}{l}\text { Bom e Não- } \\
\text { Bom }\end{array}$ & 13 & - & - & 0,29 & 0,58 & $60,60 \%$ & - & - & $93,75 \%$ & $82,47 \%$ \\
\hline & 8 & $\begin{array}{l}\text { Bom, Médio } \\
\text { e Ruim }\end{array}$ & 13 & - & - & 0,26 & 0,53 & $60,60 \%$ & $92,00 \%$ & $42,90 \%$ & - & $74,23 \%$ \\
\hline \multirow{2}{*}{$\begin{array}{c}\text { Rede Bayesia- } \\
\text { na }\end{array}$} & 9 & $\begin{array}{l}\text { Bom e Não- } \\
\text { Bom }\end{array}$ & 3 & - & - & 0,30 & 0,37 & $84,84 \%$ & - & - & $57,81 \%$ & $67,01 \%$ \\
\hline & 10 & $\begin{array}{l}\text { Bom, Médio } \\
\text { e Ruim }\end{array}$ & 5 & - & - & 0,30 & 0,41 & $60,60 \%$ & $48,00 \%$ & $100 \%$ & - & $59,79 \%$ \\
\hline
\end{tabular}

*Todos os algoritmos foram testados com 13 medidas.

Tabela 8. Resultados dos algoritmos de classificação para o subconjunto Simulação $\cap$ Ciência e Tecnologia 


\begin{tabular}{|c|c|c|c|c|c|c|c|c|c|c|c|c|}
\hline \multirow{2}{*}{$\begin{array}{l}\text { Algoritmo } \\
\text { de Classi- } \\
\text { ficação }\end{array}$} & \multirow[t]{2}{*}{$\mathbf{N}$} & \multirow{2}{*}{$\begin{array}{l}\text { Classes no } \\
\text { Modelo }\end{array}$} & \multirow{2}{*}{$\begin{array}{c}\text { Medidas } \\
\text { usadas } \\
\text { no mode- } \\
\text { 10 }\end{array}$} & \multirow{2}{*}{$\begin{array}{l}\text { Número de } \\
\text { Fo- } \\
\text { lhas/Regr } \\
\text { as }\end{array}$} & \multirow{2}{*}{$\begin{array}{l}\text { Tama- } \\
\text { nho da } \\
\text { Árvore }\end{array}$} & \multirow[t]{2}{*}{ EAM } & \multirow[t]{2}{*}{$\mathrm{K}$} & \multicolumn{5}{|c|}{ Precisão da Classificação } \\
\hline & & & & & & & & Bom & Médio & Ruim & Não-Bom & Geral \\
\hline \multirow{2}{*}{ J48 } & 1 & $\begin{array}{l}\text { Bom e Não- } \\
\text { Bom }\end{array}$ & 2 & 4 & 7 & 0,36 & 0,44 & 58,1 & - & - & $84,6 \%$ & $74,70 \%$ \\
\hline & 2 & $\begin{array}{l}\text { Bom, Médio } \\
\text { e Ruim }\end{array}$ & 4 & 8 & 15 & 0,26 & 0,47 & 64,5 & $89,1 \%$ & 0 & - & $73,49 \%$ \\
\hline \multirow{2}{*}{$\begin{array}{l}\text { Simple } \\
\text { Cart }\end{array}$} & 3 & $\begin{array}{l}\text { Bom e Não- } \\
\text { Bom }\end{array}$ & 1 & 2 & 3 & 0,40 & 0,37 & 48,4 & - & - & $86,5 \%$ & $72,29 \%$ \\
\hline & 4 & $\begin{array}{l}\text { Bom, Médio } \\
\text { e Ruim }\end{array}$ & 1 & 2 & 3 & 0,32 & 0,32 & 48,4 & $87,0 \%$ & 0 & - & $66,26 \%$ \\
\hline \multirow[b]{2}{*}{ PART } & 5 & $\begin{array}{l}\text { Bom e Não- } \\
\text { Bom }\end{array}$ & 5 & 5 & - & 0,30 & 0,55 & 54,8 & - & - & $96,2 \%$ & $80,72 \%$ \\
\hline & 6 & $\begin{array}{l}\text { Bom, Médio } \\
\text { e Ruim }\end{array}$ & 5 & - & - & 0,23 & 0,55 & 77,4 & $87,0 \%$ & 0 & - & $77,11 \%$ \\
\hline \multirow{2}{*}{$\begin{array}{l}\text { Rede Neu- } \\
\text { ral Multi- } \\
\text { layer Per- } \\
\text { ceptron }\end{array}$} & 7 & $\begin{array}{l}\text { Bom e Não- } \\
\text { Bom }\end{array}$ & 11 & - & - & 0,42 & 0,17 & 16,1 & - & - & $98,1 \%$ & $67,47 \%$ \\
\hline & 8 & $\begin{array}{l}\text { Bom, Médio } \\
\text { e Ruim }\end{array}$ & 11 & - & - & 0,34 & 0,13 & 16,1 & $97,8 \%$ & 0 & - & $60,24 \%$ \\
\hline \multirow{2}{*}{$\begin{array}{l}\text { Rede Baye- } \\
\text { siana }\end{array}$} & 9 & $\begin{array}{l}\text { Bom e Não- } \\
\text { Bom }\end{array}$ & 0 & - & - & 0,47 & 0 & 0 & - & - & $100 \%$ & $62,65 \%$ \\
\hline & 10 & $\begin{array}{l}\text { Bom, Médio } \\
\text { e Ruim }\end{array}$ & 0 & - & - & 0,37 & 0 & 0 & $100 \%$ & 0 & - & $55,42 \%$ \\
\hline
\end{tabular}

*Todos os algoritmos foram testados com 11 medidas

Tabela 9. Resultados dos algoritmos de classificação para o subconjunto Simulação $\cap$ Matemática e Estatística 


\begin{tabular}{|c|c|c|c|c|c|c|c|c|c|c|c|c|}
\hline \multirow{2}{*}{$\begin{array}{l}\text { Algoritmo } \\
\text { de Classi- } \\
\text { ficação }\end{array}$} & \multirow[t]{2}{*}{$\mathbf{N}$} & \multirow{2}{*}{$\begin{array}{c}\text { Classes no Mo- } \\
\text { delo }\end{array}$} & \multirow{2}{*}{$\begin{array}{l}\text { Medidas } \\
\text { usadas } \\
\text { no mode- } \\
\text { 10 * }\end{array}$} & \multirow{2}{*}{$\begin{array}{c}\text { Número de } \\
\text { Fo- } \\
\text { lhas/Regr } \\
\text { as }\end{array}$} & \multirow{2}{*}{$\begin{array}{l}\text { Tamanho } \\
\text { da Ár- } \\
\text { vore }\end{array}$} & \multirow[t]{2}{*}{ EAM } & \multirow[t]{2}{*}{$\mathbf{K}$} & \multicolumn{5}{|c|}{ Precisão da Classificação } \\
\hline & & & & & & & & Bom & Médio & Ruim & Não-Bom & Geral \\
\hline \multirow[b]{2}{*}{ J48 } & 1 & Bom e Não-Bom & 3 & 6 & 11 & 0,25 & 0,62 & $60,7 \%$ & - & - & $96,4 \%$ & $84,34 \%$ \\
\hline & 2 & $\begin{array}{l}\text { Bom, Médio e } \\
\text { Ruim }\end{array}$ & 2 & 4 & 7 & 0,37 & 0,21 & 0 & $97,2 \%$ & $47,4 \%$ & - & $53,01 \%$ \\
\hline \multirow{2}{*}{$\begin{array}{l}\text { Simple } \\
\text { Cart }\end{array}$} & 3 & Bom e Não-Bom & 0 & 1 & 1 & 0,45 & 0 & 0 & - & - & $100 \%$ & $66,26 \%$ \\
\hline & 4 & $\begin{array}{l}\text { Bom, Médio e } \\
\text { Ruim }\end{array}$ & 5 & 10 & 19 & 0,24 & 0,64 & $82,1 \%$ & $83,3 \%$ & $57,9 \%$ & - & $77,11 \%$ \\
\hline \multirow[b]{2}{*}{ PART } & 5 & Bom e Não-Bom & 4 & 6 & - & 0,24 & 0,66 & $67,9 \%$ & - & - & $94,5 \%$ & $85,54 \%$ \\
\hline & 6 & $\begin{array}{l}\text { Bom, Médio e } \\
\text { Ruim }\end{array}$ & 5 & 3 & - & 0,35 & 0,25 & 0 & $100 \%$ & $52,6 \%$ & - & $55,42 \%$ \\
\hline \multirow{2}{*}{$\begin{array}{l}\text { Rede Neu- } \\
\text { ral Multi- } \\
\text { layer } \\
\text { Perceptron }\end{array}$} & 7 & Bom e Não-Bom & 13 & - & - & 0,40 & 0 & 0 & - & - & $100 \%$ & $66,26 \%$ \\
\hline & 8 & $\begin{array}{l}\text { Bom, Médio e } \\
\text { Ruim }\end{array}$ & 13 & - & - & 0,38 & 0,20 & $10,7 \%$ & $86,1 \%$ & $47,4 \%$ & - & $51,81 \%$ \\
\hline \multirow{2}{*}{$\begin{array}{l}\text { Rede Baye- } \\
\text { siana }\end{array}$} & 9 & Bom e Não-Bom & 0 & - & - & 0,45 & 0 & 0 & - & - & $100 \%$ & $66,26 \%$ \\
\hline & 10 & $\begin{array}{l}\text { Bom, Médio e } \\
\text { Ruim }\end{array}$ & 0 & - & - & 0,43 & 0 & 0 & $100 \%$ & 0 & - & $43,37 \%$ \\
\hline
\end{tabular}

*Todos os algoritmos foram testados com 13 medidas

Tabela 10. Resultados dos algoritmos de classificação para o subconjunto Tutorial $\cap$ Ciência e Tecnologia 


\subsection{Algoritmos de Classificação}

Tendo em vista não ser possível gerar modelos por meio de LDA para todos os 3 subconjuntos selecionados, também foram gerados modelos para a avaliação automática da qualidade dos OAs por meio de algoritmos de mineração de dados, mais especificamente utilizando algoritmos de classificação. De acordo com [22], os algoritmos de classificação tem como objetivo construir modelos capazes de associar cada registro de uma determinada base de dados a uma categoria com rótulo. Precisamente, utilizou-se o software WEKA [23] para gerar e testar modelos para a classificação de recursos entre bons e não-bons, e entre bons, médios e ruins por meio dos seguintes algoritmos de classificação: J48, SimpleCart, PART, Rede Neural Multilayer Perceptron, e Redes Bayesianas. As tabelas 8, 9 e 10 apresentam os resultados desses testes. Para todos os testes foram utilizadas as mesmas métricas anteriormente identificadas como potenciais indicadoras de qualidade (Tabela 4).

Existem diversos critérios possíveis para a avaliação de uma boa predição de modelos de classificação [24]. Aqui foram selecionados alguns para apresentar o resultado da análise. Nas tabelas, a coluna "medidas utilizadas no modelo" apresenta o número de medidas que foram incluídas no modelo gerado pelo algoritmo em questão. $\mathrm{O}$ erro absoluto médio (EAM) mede o desvio médio entre a classe prognosticada e a verdadeira classe do recurso. Quanto mais próximo de 0 (zero) é o EAM, menor é o erro de predição e melhor é o modelo. A coluna K representa a estatística Kappa; coeficiente que mede a concordância geral entre os dados observados e os dados esperados. O coeficiente varia de -1 a 1 , onde 1 significa total concordância, 0 (zero) significa nenhuma concordância, e -1 significa total discordância. Por último, as tabelas também apresentam a precisão geral do modelo e as precisões específicas para cada uma das classes. Foi adotada a medida EAM como a principal medida de qualidade do modelo, i.e., quando se menciona que um modelo é melhor para um determinado subconjunto, significa que esse modelo apresentou o menor EAM entre todos.

Como pode ser observado nas tabelas 8,9 e 10, aparentemente não existe um algoritmo de classificação que possa ser considerado o melhor para a geração de bons modelos. Os resultados variam significativamente dependendo do algoritmo usado, do subconjunto para o qual o modelo foi gerado, e das classes de qualidade incluídas no subconjunto.

\subsubsection{Simulação $\cap$ Ciência e Tecnologia}

Da mesma forma que ocorreu com os classificadores LDA, aqui os modelos também apresentaram (em geral) os melhores resultados para o subconjunto Simulação $\cap$
Ciência e Tecnologia. Para esse subconjunto, o melhor modelo foi uma árvore de decisão gerada por meio do algoritmo J48 (modelo número 2 da tabela 8 ) que foi capaz de classificar corretamente recursos entre bons, médios e ruins com uma precisão geral de $89,69 \%$, apresentando um coeficiente Kappa de 0,83 e um EAM de apenas 0,1 . Os percentuais de precisão desse modelo para classificar recursos em categorias específicas de qualidade são consideravelmente similares. Recursos bons são classificados com uma precisão de $96,96 \%$, enquanto recursos médios e ruins são classificados com precisões de $84 \%$ e $92,85 \%$ respectivamente.

$\mathrm{O}$ segundo e o terceiro melhores modelos para esse subconjunto também estão voltados para a classificação de recursos entre bons, médios e ruins. O segundo melhor modelo foi uma árvore de decisão gerada pelo algoritmo SimpleCart que apresentou uma precisão geral de $85,57 \%$ (modelo número 4 da tabela 8 ) e o terceiro melhor modelo foi um conjunto de regras se-então gerado pelo algoritmo PART e que apresentou uma precisão geral de $83,51 \%$ (modelo número 6 da tabela 8). A principal diferença desses dois modelos (em termos de precisão) é que o primeiro apresentou uma precisão pior para classificação de recursos ruins $(71,40 \%)$ enquanto o último apresentou uma precisão pior para classificação de recursos médios (72\%). Por último, os melhores resultados para classificar OAs entre bons e não-bons foram alcançados pelo algoritmo PART e por uma Rede Neural Multilayer Perceptron. O algoritmo PART alcançou uma precisão geral de 76,26\%, um EAM de 0,28 e um coeficiente Kappa de 0,38. Ainda, o modelo classificou recursos nãobons com uma precisão de $98,43 \%$, e recursos bons com uma precisão de apenas 33,33\%. A Rede Neural Multilayer Perceptron apresentou uma precisão geral de $82,47 \%$, um EAM de 0,29 e um coeficiente Kappa de 0,58. A desvantagem desses dois modelos é a precisão extremamente baixa para classificar corretamente recursos bons.

\subsubsection{Simulação $\cap$ Matemática e Estatística}

Para o subconjunto Simulação $\cap$ Matemática e Estatística, o melhor modelo foi gerado pelo algoritmo PART (modelo 5 da tabela 9) para classificar recursos entre bons e não-bons. Esse modelo contém um conjunto de 5 regras se-então que utilizam 5 das 11 medidas identificadas como possíveis indicadores de qualidade. O modelo alcançou uma precisão geral de $80,72 \%$, um EAM de 0,30 e um coeficiente Kappa de 0,55. Apesar dos resultados gerais desse modelo poderem ser considerados bons, o modelo apresenta uma séria limitação para a classificação de recursos bons, com uma precisão de apenas $54,8 \%$. Coincidentemente, a tentativa anterior de gerar modelos LDA para esse subconjunto apenas atingiu resultados significantes para a classificação entre recursos bons e não-bons (veja modelo número 2 da tabela 6). Em 
realidade, ambos modelos apresentaram percentuais de precisão muito similares. O segundo melhor modelo para esse subconjunto foi uma árvore de decisão gerada por meio do algoritmo J48 para classificar recursos entre bons e não-bons (modelo número 1 da tabela 9). Esse modelo atingiu uma precisão geral de 74,70\%, um EAM de 0,36 e um coeficiente Kappa de 0,44. O principal problema desse modelo é o fato de ter utilizado apenas 2 das 11 medidas identificadas como possíveis indicadores de qualidade. Para esse subconjunto, todos os modelos para classificação de OAs entre bons, médios e ruins falharam completamente na classificação de recursos da classe ruins (apresentando 0\% de precisão). Também é possível perceber que as precisões para a classificação de recursos bons e médios para esses modelos são bastante similares às precisões para classificação de OAs entre bons e não-bons dos demais modelos.

\subsubsection{Tutorial $\cap$ Ciência e Tecnologia}

O melhor modelo para o subconjunto Tutorial $\cap \mathrm{Ci}$ ência e Tecnologia foi gerado pelo algoritmo PART para classificar recursos entre bons e não-bons (modelo 5 da tabela 10). O modelo apresentou uma precisão geral de $85,54 \%$, um EAM de 0,24 e um coeficiente Kappa de 0,66 . Das 13 medidas identificadas como possíveis indicadores de qualidade, o modelo utilizou apenas 4 nas 6 regras se-então geradas. Ainda, o modelo possui uma alta precisão para classificar OAs não-bons (94,5\%), mas uma baixa precisão para classificar OAs bons $(67,9 \%)$. O segundo melhor modelo foi uma árvore de decisão gerada pelo algoritmo SimpleCart para classificar recursos entre bons, médios e ruins (modelo 4 da tabela 10). Esse modelo utiliza 5 das 13 medidas identificadas como indicadores de qualidade; apresenta uma precisão geral de $77,11 \%$, um EAM de 0,24 e um coeficiente Kappa de 0,64 . O modelo é capaz de classificar recursos bons com uma precisão de $82,1 \%$, recursos médios com uma precisão de $83,3 \%$, e recursos ruins com uma precisão de $57,9 \%$. O terceiro melhor modelo é uma árvore de decisão gerada pelo algoritmo J48 (modelo 1 da tabela 10). Esse modelo classifica recursos entre bons e não-bons com uma precisão geral de 84,34\%, um EAM de 0,25, e um coeficiente Kappa de 0,62. O modelo utiliza somente 3 das 13 medidas identificadas como indicadores de qualidade. Ainda, de maneira similar ao melhor modelo para esse subconjunto, esse modelo também apresenta uma alta precisão para classificar OAs não-bons $(96,4 \%)$ e uma baixa precisão para classificar recursos bons $(60,7 \%)$.

\subsection{Considerações gerais sobre os resultados}

Praticamente todos os modelos para classificação de recursos entre bons e não-bons apresentaram uma maior precisão para a classificação de recursos não-bons. Ain- da, os modelos normalmente excluem diversas medidas previamente identificadas como possíveis indicadores de qualidade. Por exemplo, dos 10 melhores modelos, apenas 1 utilizou todas as medidas incluídas na base de dados (uma Rede Neural Multilayer Perceptron para o subconjunto Simulação $\cap$ Ciência e Tecnologia). Os demais modelos utilizaram apenas de 1 a 5 medidas. Também é interessante ressaltar que foi possível gerar modelos para todos os subconjuntos.

Os melhores modelos para classificar recursos entre bons, médios e ruins alcançaram menores EAMs e maiores coeficientes Kappa do que os modelos para classificar recursos entre bons e não-bons. Ainda, os modelos também tendem a utilizar mais indicadores de qualidade. $\mathrm{O}$ principal problema encontrado para esse conjunto de modelos é o fato de não ter sido possível criar bons modelos para o subconjunto Simulação $\cap$ Matemática e Estatística (todos os modelos apresentaram 0\% de precisão para classificar recursos ruins). Outro aspecto importante de ressaltar é que os 3 melhores modelos apresentaram precisões mais "equilibradas" para a classificação entre as diferentes classes de qualidade. Entretanto, ainda é possível observar todos os tipos de modelos, desde aqueles que classificam de maneira mais precisa recursos bons, até aqueles que classificam de maneira mais precisa recursos médios e ruins.

Os resultados encontrados nesse estudo apontam a possibilidade de gerar modelos para a avaliação automática da qualidade de OAs dentro de repositórios com base em suas medidas intrínsecas. Entretanto, como os modelos gerados são extremamente heterogêneos (diferentes EAMs, coeficientes Kappa, número de medidas utilizadas e precisões de classificação), a decisão de qual modelo é o melhor irá depender da combinação de alguns fatores, como por exemplo: o cenário específico em que o modelo será utilizado, o subconjunto (categoria de disciplina versus tipo de material) para o qual o modelo está sendo gerado, e as classes de qualidade incluídas nos dados (e.g., bom, médio, etc). A próxima seção irá descrever de forma breve dois possíveis cenários para a utilização de modelos para a avaliação automática da qualidade.

\section{Cenários de Utilização dos Mo- delos}

Como mencionado durante este trabalho, os modelos para avaliação automática da qualidade servem para serem utilizados em uma análise preliminar dos recursos, de maneira a aliviar o trabalho manual. Nesta seção serão brevemente descritos 2 possíveis cenários para a utilização dos modelos (uma vez que os mesmos estejam devidamente implementados dentro do repositório). Cada um dos cenários envolve um ator diferente e acontece em um estágio particular do ciclo de vida de um OA. A tabela 11 
resume os principais aspectos de cada um dos cenários apresentados a seguir.

\subsection{Cenário 1 - Melhorando o Projeto de um Objeto de Aprendizagem}

Modelos e perfis estatísticos de OAs podem conter informações úteis para os criadores que desejam ter uma avaliação preliminar de seus materiais com o objetivo de melhorá-los. Durante a fase de obtenção (ou criação) [25] do OA, o autor poderia fornecer para a ferramenta, informações relacionadas a disciplina e o tipo de material do recurso, e ter acesso a uma avaliação preliminar da qualidade do mesmo com relação as características intrínsecas incluídas nos modelos. Para esse cenário, seria essencial utilizar modelos capazes de explicar o raciocínio percorrido para chegar aos resultados da classificação, como aqueles representados por meio de árvores de decisão e regras se-então. Uma vez que a avaliação preliminar é realizada, o criador pode consultar o modelo (e os perfis estatísticos dos recursos) para entender quais medidas intrínsecas do OA estão influenciando a classificação. Em [26], os autores identificaram algumas das medidas intrínsecas mais importantes para a avaliação da qualidade de alguns tipos específicos de OAs armazenados no MERLOT.

Considerando que muitos modelos apresentam grandes diferenças nos percentuais de precisão dependendo das classes utilizadas nos conjuntos de dados, e dependendo das diferentes categorias de disciplinas e tipos de materiais, seria também necessário selecionar o modelo mais adequado levando em consideração tais aspectos. Por exemplo, um modelo que é bom para classificar OAs bons e ruim para classificar recursos não-bons possui grandes chances de classificar como bom um recurso que em realidade é não-bom. Tal situação levaria o criador a acreditar que seu OA já está bom, fazendo com que o mesmo perdesse a oportunidade de melhorar o recurso antes de sua publicação. Por outro lado, a classificação equivocada de um recurso bom como não-bom provavelmente faria com que o criador perdesse tempo procurando por problemas no recurso que não necessariamente existem.

Considerando que diversos modelos podem existir (alguns mais apropriados para classificar recursos bons e outros para classificar recursos não-bons), também seria possível oferecer ao criador a possibilidade de escolher para utilização os modelos que ele considera mais adequados para suas necessidades.

\subsection{Cenário 2 - Fornecendo Pontuações Internas e Ocultas}

Sabe-se que repositórios de OAs normalmente utili- zam informações avaliativas para ranquear os recursos durante o processo de busca e recuperação [27]. Entretanto, a quantidade de recursos dentro dos repositórios cresce mais rapidamente que o número de avaliações fornecidas pela comunidade de usuários e especialistas dos mesmos [28]. Por essa razão, muitos OAs que não possuem nenhuma avaliação de qualidade acabam recebendo posições ruins no processo de ranqueamento (mesmo quando os mesmos são de boa qualidade), permanecendo sem serem utilizados (ou sem serem vistos) dentro do repositório até o momento em que alguém decida avaliálos.

Os modelos desenvolvidos nesse trabalho podem ser utilizados para fornecer pontuações internas para aqueles recursos ainda não avaliados, ajudando assim o repositório durante a fase de oferta [25] dos recursos. OAs recentemente adicionados ao repositório seriam extremamente beneficiados por esse mecanismo uma vez que tais recursos raramente recebem algum tipo de avaliação imediatamente após sua inserção. A partir do momento que o OA recebe uma avaliação formal da comunidade do repositório, as pontuações implícitas fornecidas pelos modelos poderiam ser desconsideradas. Ainda, ambos tipos de avaliações (implícitas e pontuações reais) poderiam ser contrastadas de maneira a observar possíveis correlações entre as mesmas, permitindo assim avaliar a utilidade e a qualidade dos modelos.

Como os modelos seriam utilizados dentro do repositório e as classificações serviriam apenas como informações de entrada para os mecanismos de busca, não é essencialmente necessário que os modelos sejam capazes de fornecer explicações sobre o seu raciocínio. Modelos constituídos de redes neurais, funções matemáticas (LDA), ou redes bayesianas poderiam perfeitamente ser utilizados nesse cenário. Ainda, diferentes modelos ou pontuações geradas pelos mesmos poderiam ser combinados de maneira a formar uma única nota (pontuação).

Por último, as precisões dos modelos também devem ser levadas em consideração no momento de selecionar os modelos mais apropriados para esse cenário. A situação menos danosa parece ocorrer quando um modelo classifica como não-bom um material bom. Nessa situação, bons materiais iriam permanecer "escondidos" no repositório, i.e., em posições ruins no ranqueamento (uma situação similar a situação em que o modelo simplesmente não é utilizado). Por outro lado, caso o modelo classifique como bom um recurso que é não-bom, é muito provável que esse recurso seja colocado em uma posição alta no ranqueamento, aumentando assim suas chances de ser acessado pelos usuários. Essa situação levaria o usuário a selecionar um recurso de uma qualidade não tão boa, colocando em descrédito o mecanismo de ranqueamento. 


\begin{tabular}{|c|c|c|}
\hline Aspecto & $\begin{array}{l}\text { Cenário } 1 \\
\text { Melhorando o Projeto de um ob- } \\
\text { jeto de Aprendizagem }\end{array}$ & $\begin{array}{l}\text { Cenário } 2 \\
\text { Fornecendo Pontuações Internas e } \\
\text { Ocultas }\end{array}$ \\
\hline Ator Principal & Criador do OA (Autor) & Repositório \\
\hline $\begin{array}{l}\text { Etapa no Ciclo de Vida de } \\
\text { um OA }\end{array}$ & obtenção (ou Criação) & Oferta \\
\hline Modelos mais adequados & $\begin{array}{l}\text { Modelos capazes de explicar o } \\
\text { raciocínio por trás de seus } \\
\text { resultados de classificação, } \\
\text { tais como árvores de decisão e } \\
\text { regras se-então. }\end{array}$ & $\begin{array}{l}\text { Não há a necessidade de explicar a } \\
\text { classificação realizada. É possí- } \\
\text { vel utilizar modelos representados } \\
\text { por redes neurais, redes bayesia- } \\
\text { nas e funções matemáticas. }\end{array}$ \\
\hline Objetivos (Vantagens) & $\begin{array}{l}\text { Oferecer uma avaliação prelimi- } \\
\text { nar da qualidade de maneira a } \\
\text { permitir que o autor possa me- } \\
\text { lhorar seu material. }\end{array}$ & $\begin{array}{l}\text { Fornecer pontuações internas para } \\
\text { objetos de aprendizagem ainda não } \\
\text { pontuados e já armazenados no re- } \\
\text { positório de maneira a possuir } \\
\text { mais informações avaliativas du- } \\
\text { rante o processo de busca e oferta } \\
\text { (ranqueamento). }\end{array}$ \\
\hline $\begin{array}{l}\text { Problemas oriundos de uma } \\
\text { classificação equivocada de } \\
\text { OAs bons. }\end{array}$ & $\begin{array}{l}\text { O criador provavelmente perde- } \\
\text { ria algum tempo tentando melho- } \\
\text { rar um recurso que já está bom. }\end{array}$ & $\begin{array}{l}\text { O recurso permaneceria "invisível" } \\
\text { dentro do repositório, i.e., fica- } \\
\text { ria em uma posição ruim de ranque- } \\
\text { amento após o processo de busca e } \\
\text { oferta. }\end{array}$ \\
\hline $\begin{array}{l}\text { Problemas oriundos de uma } \\
\text { classificação equivocada de } \\
\text { recursos não-bons. }\end{array}$ & $\begin{array}{l}\text { O criador do recurso iria acre- } \\
\text { ditar que seu material já está } \\
\text { bom e perderia uma oportunidade } \\
\text { de melhorá-lo. }\end{array}$ & $\begin{array}{l}\text { O repositório aumentaria as chan- } \\
\text { ces de um recurso não-bom ser se- } \\
\text { lecionado pelo usuário. O mecanis- } \\
\text { mo de ranqueamento poderia cair em } \\
\text { descrédito. }\end{array}$ \\
\hline
\end{tabular}

Tabela 11. Resumo dos aspectos para cada cenário de aplicação dos modelos

\section{Considerações Finais}

O presente trabalho avaliou modelos para a avaliação automática da qualidade de OAs do repositório MERLOT. Precisamente, foram criados perfis estatísticos de recursos pontuados dentro do repositório tomando como base algumas de suas características intrínsecas. Os recursos para os quais os modelos foram gerados pertenciam aos seguintes subconjuntos: Simulação $\cap$ Ciência e Tecnologia, Simulação $\cap$ Matemática e Estatística, Tutorial $\cap$ Ciência e Tecnologia.

Esses perfis foram então utilizados para gerar modelos para a avaliação automática da qualidade por meio de Análise Discriminante Linear e 5 diferentes algoritmos mineração de dados para a tarefa de classificação, gerando resultados preliminares que apontam inicialmente para a viabilidade de tal metodologia. Entretanto, o tipo do modelo irá provavelmente depender do subconjunto específico para o qual o mesmo está sendo gerado (catego- ria de disciplina versus tipo de material). Infelizmente, a base de dados atualmente disponível para esse estudo não contém instâncias suficientes para testar essa abordagem para todos os subconjuntos possíveis existentes.

O presente trabalho apresenta algumas limitações. Por exemplo, nesse momento é difícil estabelecer as razões pelas quais algumas medidas apresentaram associação com a qualidade dos OAs. De fato, correlação não significa necessariamente causação [29] e não é possível assegurar que as associações encontradas aqui são estabelecidas por uma relação de causa e consequência entre a qualidade dos recursos (pontuações) e tais medidas. Ainda, é possível que algumas das associações encontradas estejam sendo causadas por eventos escondidos e casuais. Estudos futuros mais controlados ainda precisam ser realizados para responder essas questões abertas. Por último, esse estudo não diferencia recursos que são páginas web daqueles que não são. Ainda que a grande maioria dos OAs disponíveis no MERLOT sejam formados 
por páginas web, alguns são apenas Applets ou animações em Flash, por exemplo. Nesses casos o conteúdo disponível dentro do material está sendo desconsiderado, e o recurso está sendo computado como uma das diferentes medidas incluídas no estudo. Esse é um problema difícil de resolver, uma vez que as informações contidas dentro desses tipos de recursos estão normalmente fechadas e inacessíveis.

Para poder avaliar melhor o potencial da abordagem utilizada nesse trabalho, seria necessário trabalhar com uma amostra maior de dados do repositório (a amostra utilizada aqui corresponde a aproximadamente $25 \%$ do tamanho do repositório).

Trabalhos futuros deverão testar uma quantidade maior de medidas ainda não implementadas no crawler, tais como: o número de cores e os diferentes estilos de fontes, a existência de anúncios, o número de links redundantes e quebrados, e algumas medidas de legibilidade (e.g. índice Gunning Fog e nível Flesch-Kincaid). Ainda, como apontado por [28], ambas as comunidades de avaliadores no MERLOT (usuários e especialistas) estão comunicando diferentes visões com relação a qualidade dos OAs referenciados no repositório. Os modelos testados no presente estudo estão relacionados com a qualidade desde o ponto de vista dos especialistas. Trabalhos futuros deverão tentar desenvolver modelos utilizando os perfis estatísticos criados com as avaliações de OAs fornecidas pela comunidade de usuários. Ainda, considerando que esse trabalho é dependente do contexto, é também importante avaliar se essa abordagem pode ser estendida para outros repositórios. Como nem todos repositórios adotam o mesmo tipo de garantia de qualidade, é necessário encontrar medidas alternativas para contrastar as classes de qualidade bons e não-bons. Em um recente trabalho [30], os autores utilizaram o número de lentes (lenses) do repositório Connexions ${ }^{1}$ como base para a construção de tais perfis e geração dos modelos, mas devido ao ainda pequeno número de lentes existentes no repositório, chegaram a resultados inconclusivos. Outra direção interessante para trabalhos futuros é classificar os OAs de acordo com sua granularidade e utilizar essa informação como uma das medidas que são avaliadas durante o processo de criação dos perfis estatísticos.

É importante mencionar que a presente proposta não tem a intenção de substituir os métodos tradicionais de avaliação da qualidade de OAs, mas apenas complementar os mesmos oferecendo uma avaliação preliminar útil e de baixo custo antes de realizar uma avaliação mais demorada e consumidora de recursos humanos.

\section{Referências}

[1] P. Díaz, M.-Á. Sicilia, and I. Aedo, "Evaluation of Hypermedia Educational Systems: Criteria and Imperfect Measures," in International Conference on Computers in Education (ICCE'02), Auckland, New Zealand, 2002, pp. 621-626

[2] R. Kay and L. Knaack, "Assessing learning, quality and engagement in learning objects: the Learning Object Evaluation Scale for Students (LOES-S)," Educational Technology Research and Development, vol. 57, pp. 147-168, 2009.

[3] J. C. Nesbit, K. Belfer, and T. Leacock, "Learning object review instrument (LORI)," ed. E-learning research and assessment network. Retrieved from http://www.elera.net/eLera/Home/Articles/LORI\% 20manual, 2003.

[4] J. C. Nesbit, K. Belfer, and J. Vargo, "A Convergent Participation Model for Evaluation of Learning Objects," Canadian Journal of Learning and Technology, vol. 28, 2002.

[5] J. Vargo, J. C. Nesbit, K. Belfer, and A. Archambault, "Learning Object Evaluation: Computer-Mediated Collaboration and Inter-Rater Reliability," International Journal of Computers and Applications, vol. 25, pp. 1-8, 2003.

[6] D. D. Williams, "Evaluation of learning objects and instruction using learning objects," in The Instructional Use of Learning Objects: Online Version, D. A. Wiley, Ed., ed, 2000.

[7] X. Ochoa and E. Duval, "Quantitative Analysis of Learning Object Repositories," Learning Technologies, IEEE Transactions on, vol. 2, pp. 226-238, 2009.

[8] R. Vuorikari, N. Manouselis, and E. Duval, "Using Metadata for Storing, Sharing and Reusing Evaluations for Social Recommendations: the Case of Learning Resources," Social Information Retrieval Systems: Emerging Technologies and Applications for Searching the Web Effectively. Hershey, PA: Idea Group Publishing, pp. 87-107, 2008.

[9] M. Y. Ivory and M. A. Hearst, "Statistical profiles of highly-rated web sites," presented at the Proceedings of the SIGCHI conference on Human factors in computing systems: Changing our world, changing ourselves, Minneapolis, Minnesota, USA, 2002.

[10] C. Cechinel, S. Sánchez-Alonso, and E. GarcíaBarriocanal, "Statistical profiles of highly-rated learning objects," Computers \& Education, vol. 57, pp. 1255-1269, 2011.

${ }^{1}$ http://cnx.org/ 
[11] C. Cechinel, S. Sánchez-Alonso, M.-Á. Sicilia, and C. V. Amador, "Evaluating Models for Automated Quality Assessment of Learning Objects inside Repositories," presented at the 6th Latin American Conference on Learning Objects and Technology Enhanced Learning - LACLO 2011 Montevideo - Uruguay, 2011.

[12] X. Ochoa and E. Duval, "Relevance Ranking Metrics for Learning Objects," Learning Technologies, IEEE Transactions on, vol. 1, pp. 34-48, 2008.

[13] E. Duval, "LearnRank: Towards a real quality measure for learning," in Handbook on Quality and Standardisation in E-Learning, U.-D. Ehlers and J. M. Pawlowski, Eds., ed: Springer Berlin Heidelberg, 2006, pp. 457-463.

[14] M. Meyer, A. Hannappel, C. Rensing, and R. Steinmetz, "Automatic classification of didactic functions of e-learning resources," presented at the Proceedings of the 15th international conference on Multimedia, Augsburg, Germany, 2007.

[15] E. Mendes, W. Hall, and R. Harrison, "Applying Metrics to the Evaluation of Educational Hypermedia Applications," Journal of Universal Computer Science, vol. 4, pp. 382-403, 1998.

[16] S. Bethard, P. Wetzer, K. Butcher, J. H. Martin, and T. Sumner, "Automatically characterizing resource quality for educational digital libraries," presented at the Proceedings of the 9th ACM/IEEE-CS joint conference on Digital libraries, Austin, TX, USA, 2009.

[17] J. E. Blumenstock, "Size matters: word count as a measure of quality on wikipedia," presented at the Proceedings of the 17th international conference on World Wide Web, Beijing, China, 2008.

[18] R. Cafolla, "Project MERLOT: Bringing Peer Review to Web-Based Educational Resources," Journal of Technology and Teacher Education, vol. 14, pp. 313-323, 2006.

[19] M.-Á. Sicilia, S. Sánchez-Alonso, E. GarcíaBarriocanal, and D. Rodriguez-Garcia, "Exploring Structural Prestige in Learning Object Repositories: Some Insights from Examining References in MERLOT," in International Conference on Intelligent Networking and Collaborative Systems, 2009. INCOS '09. , 2009, pp. 212-218.

[20] M. R. Fernández, "Métricas en repositorios de objetos de aprendizaje," Bachelor Final Project, Computer Science Department, University of Alcalá, Alcalá de Henares, Spain, 2011.
[21] C. Cechinel, S. Sánchez-Alonso, M.-Á. Sicilia, and M. C. Mattos, "Descriptive Analysis of Learning Object Material Types in MERLOT," in Metadata and Semantic Research. vol. 108, S. Sánchez-Alonso and I. N. Athanasiadis, Eds., ed: Springer Berlin Heidelberg, 2010, pp. 331-341.

[22] R. Goldschmidt and E. Passos, Data Mining: um guia prático. Rio de Janeiro: Elsevier, 2005.

[23] M. Hall, E. Frank, G. Holmes, B. Pfahringer, P. Reutemann, and I. H. Witten, "The WEKA data mining software: an update," SIGKDD Explor. Newsl., vol. 11, pp. 10-18, 2009.

[24] P. Cichosz, "Assessing the quality of classification models: Performance measures and evaluation procedures," Central European Journal of Engineering, vol. 1, pp. 132-158, 2011.

[25] B. Collis and A. Strijker, "Technology and Human Issues in Reusing Learning Objects," Journal of Interactive Media in Education; May 2004: JIME Special Issue on the Educational Semantic Web, vol. 2004, 2004.

[26] C. Cechinel, S. Silva Camargo, S. SánchezAlonso, and M.-Á. Sicilia, "On the Search for Intrinsic Quality Metrics of Learning Objects," in Metadata and Semantics Research, J. Dodero, M. Palomo-Duarte, and P. Karampiperis, Eds., ed: Springer Berlin Heidelberg, 2012, pp. 49-60.

[27] Sanz-Rodríguez, J. M. Dodero, and S. SánchezAlonso, "Ranking Learning Objects through Integration of Different Quality Indicators," IEEE Transactions on Learning Technologies, vol. 3, pp. 358 - 363, Oct.-Dec. 20102010.

[28] C. Cechinel and S. Sánchez-Alonso, "Analyzing Associations between the Different Ratings Dimensions of the MERLOT Repository," Interdisciplinary Journal of E-Learning and Learning Objects vol. 7, pp. 1-9, 2011.

[29] P. Holland, "Statistics and Causal Inference," Journal of the American Statistical Association, vol. 81, pp. 945-960, 1986.

[30] C. Cechinel, S. Sánchez-Alonso, M.-Á. Sicilia, and P. W. T. d. A. Simões, "Exploring the Development of Endorsed Learning Resources Profiles in the Connexions Repository," in Metadata and Semantic Research. vol. 240, E. García-Barriocanal, Z. Cebeci, M. C. Okur, and A. Öztürk, Eds., ed: Springer Berlin Heidelberg, 2011, pp. 12-21. 